\title{
Hepatitis C Virus: A Review of Treatment Guidelines, Cost-effectiveness, and Access to Therapy
}

\author{
Shaina M. Lynch* and George Y. Wu \\ Department of Medicine, Division of Gastroenterology-Hepatology, University of Connecticut Health Center, Hartford, USA
}

\begin{abstract}
Hepatitis $\mathrm{C}$ virus (HCV) infection remains a significant medical concern in the United States and around the world. It is still one of the leading causes of chronic liver disease, and, for more than 20 years, there has been little progress in the treatment of $\mathrm{HCV}$ infection. The advent of direct-acting antivirals (DAAs) initiated the era of high efficacy and well-tolerated medications with high cure rates. The efficacy of these medications has prompted many professional societies around the world to update their treatment guidelines to include DAAs as first-line treatment. Guidelines by the American Association for the Study of Liver Disease/Infectious Disease Society of America, World Health Organization, Asian-Pacific Association for the Study of Liver and the European Association for the Study of Liver have all incorporated DAAs into their treatment guidelines. Despite the promising data supporting these medications, however, their cost represents a limiting factor to their use, even though studies have shown DAAs to be cost-effective. In addition to the expense of these medications and limited resources, there are many barriers preventing patients from receiving this potentially life-saving treatment. In order to overcome these barriers, these issues need to be recognized and addressed.

(c) 2016 The Second Affiliated Hospital of Chongqing Medical University. Published by XIA \& HE Publishing Inc. All rights reserved.
\end{abstract}

\section{Introduction}

Hepatitis C virus (HCV) infection is a significant medical concern in the United States and around the world. HCVrelated complications cause 350,000 global deaths annually

Keywords: Hepatitis C; HCV; Drug therapy; Health care costs.

Abbreviations: HCV, hepatitis C virus; US, United States; DAAs, direct-acting antivirals; AASLD, American Association for the Study of Liver Diseases; IDSA infectious Disease Society of America; APASL, Asian Pacific Association for the Study of Liver; EASL, European Association for the Study of Liver; SVR, sustained virological response; PegIFN, pegylated interferon; WHO, World Health Organization; ProD, Paritaprevir/ritonavir/ombitasvir/dasabuvir; PPIs, Proton pump inhibitors; RAVs, resistance-associated variants; FDA, Food and Drug Administration RBV, Ribavirin; HIV, human immunodeficiency virus; TDF, tenofovir disoproxi fumarate; TAF, tenofovir alafenamide; $\mathrm{CrCl}$, creatinine clearance; eGFR, estimated glomerular filtration rate; HD, hemodialysis; LMIC, low- and middle-income countries; GNI, gross national income; CMS, center for Medicaid and Medicare Services; PBM, pharmacy benefit manager; CEA, cost effectiveness analysis; ICER, incremental cost-effectiveness ratio; QALY, quality-adjusted life years.

Received: 12 July 2016; Revised: 03 October 2016; Accepted: 05 October 2016 DOI: $10.14218 / \mathrm{JCTH} .2016 .00027$.

*Correspondence to: Shaina M. Lynch, Department of Medicine, Saint Francis Hospital and Medical Center, 114 Woodland Street, Hartford, CT 06105, USA. Tel: +1-860-714-7446, Fax: +1-860-714-1508, E-mail: Shainamlynch@gmail.com and HCV infection remains one of the leading causes of chronic liver disease. ${ }^{1,2}$ Of the over 185 million people chronically infected with $\mathrm{HCV}$, more than 4 million are in the United States alone, and the majority of these individuals are not aware of the infection. ${ }^{3-6}$ It is estimated that about one-third of those with chronic HCV infection will go on to develop liver cirrhosis or hepatocellular carcinoma. ${ }^{1}$

In 1998, the United States' Centers for Disease Control released HCV testing recommendations based on demographics, exposures, risky behaviors and certain medical conditions. Despite these recommendations, however, more than $50 \%$ of HCV infections have remained unidentified. ${ }^{6}$ The risk-based HCV testing guidelines were expanded in 2012 to include one-time testing for all persons born between 1945 and 1965, as this birth cohort (known as the "baby boomers") accounted for almost three-fourths of all HCV infections nationally. ${ }^{6,7}$ In order to make steps forward to improve transmission rates and health outcomes, it is first crucial to identify those with active infection. ${ }^{6,8}$

Identifying $\mathrm{HCV}$-infected persons has become essential since the advent of direct acting antivirals (DAAs), given their association with high cure rates, which is the primary goal of treatment. Treatment success is measured based on sustained virological response (SVR), which is defined as an undetectable level of HCV RNA at 12 weeks (SVR12) or 24 weeks (SVR24) after completion of treatment. ${ }^{9}$ The first approved DAAs, telaprevir and boceprevir, were introduced in 2011 for the treatment of HCV genotype 1 infection. Use of telaprevir and boceprevir in combination with pegylated interferon (PegIFN)- $\alpha$ and ribavirin (RBV) led to achievement of SVR rates in $65 \%-75 \%$ of patients with HCV genotype 1. Unfortunately, this improvement in SVR was associated with an increase in side effects and cost. ${ }^{9}$

The development of DAAs ushered in the era of high efficacy and well-tolerated medications for HCV infection. However, due to differences in efficacies of currently available medications based on viral factors, such as genotype and subtype, and host factors, such as liver decompensation and renal excretion issues, can complicate the selection of optimal agents. ${ }^{9}$ The purpose of this review is to compare various guidelines for the treatment of HCV infection, to evaluate the cost-effectiveness of the new treatment options (DAAs), and to identify barriers limiting access to treatment.

\section{Comparison of guidelines and DAAs}

Due to differences in endemicity, genotype and access to treatment, there is no worldwide consensus on HCV therapy. However, regional guidelines from four international organizations have been updated. We have reviewed the respective guidelines from the American Association for the Study of 
Liver Disease/Infectious Disease Society of America (AASLD/ IDSA), World Health Organization (WHO), Asian Pacific Association for the Study of the Liver (APASL) and European Association for the Study of the Liver (EASL), and compared them in Tables 1-10.

Given the high SVR rates seen with the new DAAs, it is no surprise that regimens including these drugs are recommended by the different organizations. With the exception of the EASL, the organizations generally recommend IFN-free regimens as first-line treatment options. The EASL report considered differences in per capita incomes and health insurance systems across Europe as a reason for including PegIFN- $\alpha$ in recommended treatment regimens. ${ }^{9}$ The APASL guidelines do not include IFN based on several factors. A study in Asia showed that up to $50 \%$ of patients with $\mathrm{HCV}$ are deemed unsuitable for treatment with IFN. Additionally, IFN therapy in Asian countries is often limited to major treatment centers, with limited access to isolated areas due to the infrastructure needed to ensure safety and appropriate treatment. ${ }^{10}$ According to a study by Wedemeyer et al., ${ }^{11}$ given the nature of IFN-based treatment, treatment response rates have been reported as low as $5 \%$, even in countries with diagnosis rates greater than $50 \% .{ }^{10}$

\section{Genotype 1}

For genotype $1 \mathrm{a}$ and $1 \mathrm{~b}$, the treatment regimens of sofosbuvir/ledipasvir and paritaprevir/ritonavir/ombitasvir/dasabuvir
(PrOD) are recommended by all four organizations. Additional regimens including sofosbuvir/daclatasvir, and sofosbuvir/ simeprevir are recommended by the AASLD/IDSA, EASL and WHO. ${ }^{10,12,13}$ The EASL guidelines contain two PegIFN- $\alpha$-based regimens, recommending the combination of PegIFN- $\alpha /$ sofosbuvir/RBV and PegIFN- $\alpha$ /simeprevir/RBV for treatment of genotype 1 . Given that HCV genotype $1 \mathrm{~b}$ is the predominant subtype in the Asian-Pacific region (excluding Australia, Iran, New Zealand, Philippines and Thailand), the APASL guidelines also recommend the combination of asunaprevir/daclatasvir, for which data shows efficacy against genotype $1 \mathrm{~b}$ only. The APASL guidelines also recommend the combination of grazoprevir/elbasvir for the treatment of HCV genotype $1 \mathrm{~b}$, based on a phase 2 trial showing SVR rates of $90 \%-97 \% .{ }^{6,9,10,12}$ The AASLD/IDSA guidelines recommend grazoprevir/elbasvir for genotypes $1 a$ and $1 b^{13}$ (Table $1 a, 1 b$ ).

The choice of treatment regimen is based on a number of factors, with potential drug interactions being an important consideration. The sofosbuvir/ledipasvir regimen may interact with proton pump inhibitors (PPIs), and in patients using this class of medications, one of the other HCV treatment regimens should be considered. The PrOD regimen is recommended for genotype 1 by AASLD/IDSA, EASL and APASL (genotype $1 \mathrm{~b}$ ) and safe in patients taking PPIs, but has the potential to interact with drugs that interfere with the cytochrome P450 3A4 isoenzyme, specifically salmeterol, a long-acting inhaled beta-agonist. ${ }^{14}$ Patients with HCV

Table 1a. Comparison of treatment guidelines for treatment-naïve patients infected with HCV genotype 1

\begin{tabular}{|c|c|c|c|c|}
\hline Genotype & AASLD/IDSA & EASL & $\mathrm{WHO}^{\#}$ & APASL \\
\hline $1 a$ & $\begin{array}{l}\text { - Sofosbuvir/ledipasvir (I-A) } \\
\text { - Elbasvir/grazoprevir (I-A) } \\
\text { - Sofosbuvir/velpatasvir (I-A) } \\
\text { - PrOD/RBV (I-A) } \\
\text { - Sofosbuvir/simeprevir (I-A) } \\
\text { - Sofosbuvir/daclatasvir (I-B) } \\
\text { Alternatives } \\
\text { - Sofosbuvir/simeprevir } \pm R B V^{a *} \\
\text { (II-B) } \\
\text { - Elbasvir/grazoprevir } \pm R B V^{e} \\
\text { (IIa-B) } \\
\text { - Sofosbuvir/daclatasvir } \pm R B V^{a} \\
\text { (IIa-B) }\end{array}$ & 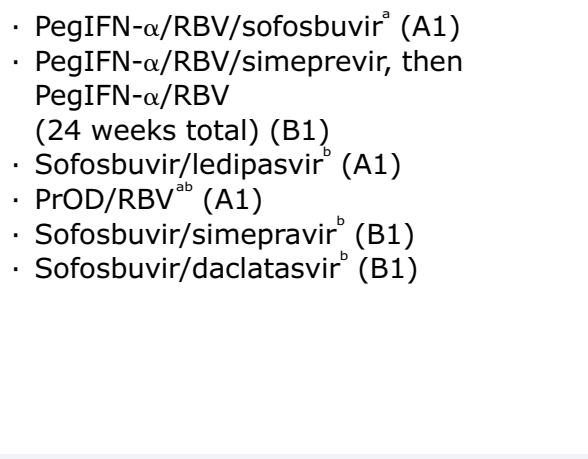 & $\begin{array}{l}\text { Sofosbuvir/ } \\
\text { daclatasvir } \\
\text { - Sofosbuvir/ } \\
\text { ledipasvir }^{\text {abcd }} \\
\text { Alternatives } \\
\text { Simeprevir/ } \\
\text { sofosbuvir }^{\text {ab* }} \\
\text { - } \text { PrOD/RBV }^{\mathrm{a}}\end{array}$ & $\begin{array}{l}\text { Sofosbuvir/ } \\
\text { ledipasvir (A1) }\end{array}$ \\
\hline $1 b$ & $\begin{array}{l}\text { - Elbasvir/grazoprevir (I-A) } \\
\text { - Ledipasvir/sofosbuvir (I-A) } \\
\text { - PrOD (I-A) } \\
\text { - Sofosbuvir/simeprevir (I-A) } \\
\text { - Sofosbuvir/velapatasvir (I-A) } \\
\text { - Sofosbuvir/daclatasvir (I-B) } \\
\text { Alternatives } \\
\text { - Sofosbuvir/daclatasvir } \pm R B V^{a} \\
\text { - Sofosbuvir/simeprevir } \pm R B V^{a} \\
\text { (IIa-B) }\end{array}$ & $\begin{array}{l}\text { - PegIFN- } \alpha / \text { RBV/sofosbuvir (A1) } \\
\text { - PegIFN- } \alpha / \text { RBV/simeprevir, then PegIFN- } \\
\alpha / \text { RBV } \\
\text { ( } 24 \text { weeks total) (B1) } \\
\text { - Sofosbuvir/ledipasvir }{ }^{b}(A 1) \\
\text { - PrOD }{ }^{b}(A 1) \\
\text { - Sofosbuvir/simepravir (A1) }(B 1) \\
\text { - Sofosbuvir/daciatasvir (A1) (B1) }\end{array}$ & $\begin{array}{l}\text { Sofosbuvir/ } \\
\text { dalatasvir }^{\text {ab }} \\
\text { - Sofosbuvir/ } \\
\text { ledipasvir }^{\text {abcd }} \\
\text { Alternatives } \\
\text { Sofosbuvir/ } \\
\text { Simepravir } \\
\text { - PrOD }\end{array}$ & $\begin{array}{l}\text { - Sofosbuvir/ } \\
\text { ledipasvir (A1) } \\
\text { - PrOD (A1) } \\
\text { - Grazoprevir/ } \\
\text { elbasvir (A1) } \\
\text { - Asunaprevir/ } \\
\text { daclatasvir } \\
\text { (24 weeks)(A2) }\end{array}$ \\
\hline
\end{tabular}

\footnotetext{
* Option in patients with a negative test result for the Q80K variant:

\# All regimens: strong recommendation, moderate quality of evidence.

a 24 weeks in patients with cirrhosis;

12 weeks with RBV in patients with cirrhosis;

${ }^{\mathrm{C}}$ Treatment may be shortened to 8 weeks in treatment-naïve persons without cirrhosis if baseline HCV RNA is below 6 million IU/mL;

d If the platelet count is $<75 \times 10^{3} / \mu \mathrm{L}$, then 24 weeks of treatment with RBV should be given;

e 16 weeks if baseline NS5A RAVs for elbasvir.

Abbreviations: PrOD, Paritaprevir/ritonavir/ombitasvir/dasabuvir; RAVs, Resistance-associated variants; RBV, Ribavirin.

All treatment courses are 12 weeks unless indicated otherwise.
} 
Lynch S.M. et al: Hepatitis C treatment, cost and barriers

Table 1b. Comparison of treatment guidelines for treatment-experienced patients infected with HCV genotype 1

\begin{tabular}{|c|c|c|c|c|}
\hline Genotype & AASLD/IDSA & EASL & $\mathrm{WHO}^{*}$ & APASL \\
\hline $1 a$ & $\begin{array}{l}\text { - Sofosbuvir/ledipasvir (I-A) } \\
\text { - Elbasvir/grazoprevir (I-A) } \\
\text { - Sofosbuvir/velpatasvir (I-A) } \\
\text { - PrOD/RBV (I-A) } \\
\text { - Sofosbuvir/simeprevir (I-A) } \\
\text { - Sofosbuvir/daclatasvir (I-B) } \\
\text { Alternatives } \\
\text { - Sofosbuvir/ledipasvir }{ }^{a}(I-A) \\
\text { - Elbasvir/grazoprevir } \pm R B V^{e}(\text { I-B) } \\
\text { - Sofosbuvir/daclatasvir } \pm R B V^{a}(\text { IIa-B) } \\
\text { - Sofosbuvir/simeprevir } \pm R B V^{a}(\text { IIa-B) }\end{array}$ & $\begin{array}{l}\text { PegIFN- } \alpha / \text { RBV/sofosbuvir (A1) } \\
\text { PegIFN- } \alpha / \text { RBV/simeprevir, then } \\
\text { PegIFN- } \alpha / \text { RBV for } 36 \text { weeks } \\
\text { (48 weeks total) (B1) } \\
\text { - Sofosbuvir/ledipasvir }{ }^{b} \text { (A1) } \\
\text { - PrOD/RBV }{ }^{\mathrm{ab}} \text { (A1) } \\
\text { - Sofosbuvir/simepravir (A1) }{ }^{\mathrm{b}}(\mathrm{B} 1) \\
\text { - Sofosbuvir/daciatasvir (A1) }\end{array}$ & $\begin{array}{l}\text { Sofosbuvir/ } \\
\text { daclatasvir }^{\text {ab }} \\
\text { - Sofosbuvir/ } \\
\text { ledipasvir }^{\text {abcd }} \\
\text { Alternatives } \\
\text { Sofosbuvir/ } \\
\text { simepravir }^{\text {sb* }} \\
\text { PrOD/RBV }\end{array}$ & $\begin{array}{l}\text { Sofosbuvir/ } \\
\text { ledipasvir for } \\
12 \text { weeks (A1) }\end{array}$ \\
\hline $1 b$ & $\begin{array}{l}\text { - Elbasvir/grazoprevir (I-A) } \\
\text { - Sofosbuvir/ledipasvir (I-A) } \\
\text { - PrOD (I-A) } \\
\text { - Sofosbuvir/simeprevir (I-A) } \\
\text { - Sofosbuvir/velapatasvir (I-A) } \\
\text { - Sofosbuvir/daclatasvir (I-B) } \\
\text { Alternatives } \\
\text { Sofosbuvir/ledipasvir }{ }^{a}(I-A) \\
\text { - Sofosbuvir/daclatasvir } \pm R B V^{a} \\
\text { - Sofosbuvir/simeprevir } \pm R B V^{a} \text { (IIa-B) }\end{array}$ & 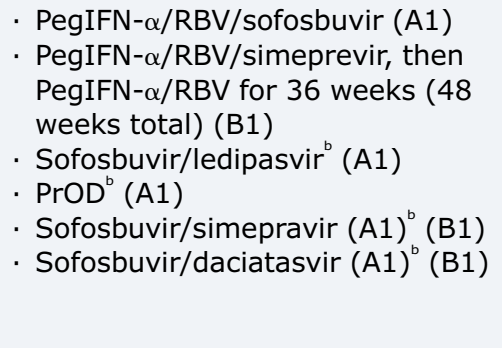 & $\begin{array}{l}\text { Sofosbuvir/ } \\
\text { daclatasvir }^{\mathrm{ab}} \\
\text { - Sofosbuvir/ } \\
\text { ledipasvir }^{\mathrm{abcd}} \\
\text { Alternatives } \\
\text { Simeprevir/ } \\
\text { sofosbuvir }^{\mathrm{ab*}} \\
\text { PrOD }\end{array}$ & $\begin{array}{l}\text { - Sofosbuvir/ } \\
\text { ledipasvir (A1) } \\
\text { - PrOD (A1) } \\
\text { - Grazoprevir/ } \\
\text { elbasvir (A1) } \\
\text { - Asunaprevir/ } \\
\text { daclatasvir } \\
\text { (24 weeks) (A2) }\end{array}$ \\
\hline
\end{tabular}

\footnotetext{
* Option in patients with a negative test result for the Q80K variant;

\# All regimens: strong recommendation, moderate quality of evidence.

a 24 weeks in patients with cirrhosis;

b 12 weeks with RBV in patients with cirrhosis;

${ }^{\mathrm{c}}$ Treatment may be shortened to 8 weeks in treatment-naïve persons without cirrhosis if baseline HCV RNA is below 6 million IU/mL;

d If the platelet count is $<75 \times 10^{3} / \mu \mathrm{L}$, then 24 weeks of treatment with RBV should be given.

Abbreviations: PegIFN, Pegylated interferon; PrOD, Paritaprevir/ritonavir/ombitasvir/dasabuvir; RBV, Ribavirin .

All treatment courses are 12 weeks unless indicated otherwise.
}

genotype 1a with the nonstructural protein 3 (NS3) Q80K polymorphism and cirrhosis showed lower SVR rates when treated with sofosbuvir and simeprevir, and one of the other treatment regimens should be used in these patients. ${ }^{6}$ In addition, the presence of baseline NS5A resistanceassociated variants (RAVs) significantly reduced the rate of SVR with a 12-week elbasvir/grazoprevir treatment regimen. Therefore, in patients with baseline NS5A RAVs the combination of elbasvir/grazoprevir should be avoided. ${ }^{13}$

\section{Genotype 2}

The combination of sofosbuvir and RBV for 12 weeks is recommended by EASL, WHO and APASL for the treatment of HCV genotype $2 .^{6,9,10,12}$ The EASL guidelines include the combination of PegIFN- $\alpha / R B V /$ sofosbuvir, which is recommended based on SVR data from the LONESTAR study. ${ }^{9}$ For RBV-intolerant individuals, sofosbuvir/daclatasvir is given as an option by EASL, WHO and APASL based on studies showing that daclatasvir is active against genotype 2 in vitro. ${ }^{9,10,12}$ The APASL guidelines also recommend the combination of sofosbuvir and velpatasvir, which was approved by the United States' Food and Drug Administration (FDA) on June $28^{\text {th }}, 2016 .^{15}$ The AASLD/IDSA guidelines recommend sofosbuvir/velaptasvir and, as an alternative, sofosbuvir/daclatasvir for both treatment-experienced and treatment-naïve patients. In treatment-experienced patients, RBV is recommended for use with sofosbuvir/velaptasvir and may be used, if desired, with daclatasvir, regardless of cirrhosis status. In patients with compensated cirrhosis, sofosbuvir/daclatasvir, given for 16 to 24 weeks, is an alternative regimen ${ }^{13}$ (Table $2 a, 2 b$ ).

\section{Genotype 3}

With current treatment options, HCV genotype 3 is the most difficult subtype to treat. ${ }^{10}$ The recently updated AASLD/IDSA guidelines recommend sofosbuvir/velpatasvir or daclastavir/ sofosbuvir for both treatment-experienced and treatmentnaïve patients, with or without cirrhosis. In treatment-naïve patients, RBV is added to either treatment with the exception of patients without cirrhosis who had failed PegIFN- $\alpha /$ RBV $^{13}$ The EASL guidelines recommend PegIFN- $\alpha$ /sofosbuvir/RBV (also given as an alternative regimen by the WHO) and, in agreement with WHO and APASL, recommend the IFN-free regimen of sofosbuvir/RBV for 24 weeks. ${ }^{6,9,10,12}$ The EASL, WHO and APASL guidelines include the option to treat with a regimen of sofosbuvir/daclatasvir with or without $\mathrm{RBV}^{9,10,12}$ (Table 3a, 3b).

\section{Genotype 4}

Generally, the treatment guidelines for HCV genotype 4 are comparable to those for genotype 1 . The combination of ledipasvir and sofosbuvir for 12 weeks is recommended by all four societies. 6,9,10,12 The AASLD/IDSA guidelines recommend similar treatments for treatment-naïve and treatment-experienced patients, with and without cirrhosis, with minor additions to the treatment regimen. The supplemented regimens include paritoprevir/ritonavir/ombitasvir/ 
Lynch S.M. et al: Hepatitis C treatment, cost and barriers

Table 2a. Comparison of treatment guidelines for treatment-naïve patients infected with HCV genotype 2

\begin{tabular}{|c|c|c|c|}
\hline AASLD/IDSA & EASL & WHO" & APASL \\
\hline $\begin{array}{l}\text { Sofosbuvir/velapatasvir (I-A) } \\
\text { Sofosbuvir/daclatasvir (IIa-B) }\end{array}$ & $\begin{array}{l}\text { - PegIFN- } \alpha / R B V / \text { sofosbuvir (B1) } \\
\text { - Sofosbuvir/RBV (A1) } \\
\text { - Sofosbuvir/daclatasvir (B1) }\end{array}$ & $\begin{array}{l}\text { Sofosbuvir/RBV } \\
\text { Alternative } \\
\text { Sofosbuvir/ } \\
\text { daclatasvir }\end{array}$ & $\begin{array}{l}\text { - Sofosbuvir/RBV (A1) } \\
\text { - Sofosbuvir/daclatasvir } \\
(24 \text { weeks) })^{*} \text { (B1) } \\
\text { - Sofosbuvir/ledipasvir* (B1) } \\
\text { - Sofosbuvir/velpatasvir* (B1) }\end{array}$ \\
\hline
\end{tabular}

* For RBV intolerant patients;

\# All regimens: strong recommendation, low quality of evidence.

a 16-24 weeks in patients with cirrhosis.

Abbreviations: PegIFN, Pegylated interferon; RBV, Ribavirin.

All treatment courses are 12 weeks unless indicated otherwise.

Table 2b. Comparison of treatment guidelines for treatment-experienced patients infected with HCV genotype 2

\begin{tabular}{|c|c|c|c|}
\hline AASLD/IDSA & EASL & WHO ${ }^{*}$ & APASL \\
\hline $\begin{array}{l}\text { Sofosbuvir/velapatasvir }(1-A)^{b} \\
\text { Sofosbuvir/daclatasvir }^{a}(\text { IIa-B) }\end{array}$ & $\begin{array}{l}\text { - PegIFN- } \alpha / \text { RBV/sofosbuvir (B1) } \\
\text { - Sofosbuvir/RBV (B1) } \\
\text { - Sofosbuvir/daclatasvir (B1) }\end{array}$ & $\begin{array}{l}\text { Sofosbuvir/RBV } \\
\text { Alternative } \\
\text { Sofosbuvir/ } \\
\text { daclatsvir }\end{array}$ & $\begin{array}{l}\text { - Sofosbuvir/RBV (A1) } \\
\text { - Sofosbuvir/daclatasvir } \\
(24 \text { weeks)* (B1) } \\
\text { - Sofosbuvir/ledipasvir* (B1) } \\
\text { - Sofosbuvir/velpatasvir* (B1) }\end{array}$ \\
\hline
\end{tabular}

\footnotetext{
* For RBV-intolerant patients;

\# All regimens: strong recommendation, low quality of evidence.

a 16-24 weeks in patients with cirrhosis;

b With RBV for 12 weeks (sofosbuvir/RBV TE);

c \pm RBV for 24 weeks (sofosbuvir/RBV TE).

Abbreviations: PegIFN, Pegylated interferon; RBV, Ribavirin.

All treatment courses are 12 weeks unless indicated otherwise.
}

Table 3a. Comparison of treatment guidelines for treatment-naïve patients infected with HCV genotype 3

\begin{tabular}{|c|c|c|c|}
\hline AASLD/IDSA & EASL & WHO" & APASL \\
\hline $\begin{array}{l}\text { Sofosbuvir/daclatasvir (I-A) } \\
\text { Sofosbuvir/velpatasvir (I-A) } \\
\text { (IIa-B) }\end{array}$ & $\begin{array}{l}\text { PegIFN- } \alpha \text { /sofosbuvir/RBV (B1) } \\
\text { - Sofosbuvir/RBV (A1) })^{\mathrm{b}}(\mathrm{B} 1)^{\mathrm{c}} \\
\text { Sofosbuvir/daclatasvir }(\mathrm{A} 1)^{\mathrm{c}}(\mathrm{B} 1)\end{array}$ & $\begin{array}{l}\text { Sofosbuvir/daclatasvir } \\
\text { - Sofosbuvir/RBV } \\
\text { Alternative } \\
\begin{array}{l}\text { Sofosbuvir/PegIFN/ } \\
\text { ribavirin }\end{array}\end{array}$ & $\begin{array}{l}\text { Sofosbuvir/RBV }{ }^{\mathrm{b}}(\mathrm{A} 1)^{\mathrm{d}}(\mathrm{B} 2) \\
\text { Sofosbuvir/daclatasvir }{ }^{\mathrm{a}}(\mathrm{A} 2)\end{array}$ \\
\hline
\end{tabular}

\footnotetext{
\# All regimens: strong recommendation, low quality of evidence.

a RBV for 24 weeks (cirrhotics);

b 24 weeks, option for non-cirrhotics;

c 24 weeks in patients with cirrhosis;

d 16 weeks in patients with cirrhosis.

Abbreviations: PegIFN, Pegylated interferon; RBV, Ribavirin.
}

All treatment courses are 12 weeks unless indicated otherwise.

Table 3b. Comparison of treatment guidelines for treatment-experienced patients infected with HCV genotype 3

\begin{tabular}{|c|c|c|c|}
\hline AASLD/IDSA & EASL & $\mathrm{WHO}^{*}$ & APASL \\
\hline $\begin{array}{l}\text { - Sofosbuvir/daclatasvir (I-A) } \\
\text { - Sofosbuvir/velpatasvir (I-A) }\end{array}$ & $\begin{array}{l}\text { - PegIFN- } \alpha / \text { RBV/sofosbuvir (B1) } \\
\text { - Sofosbuvir/RBV (A1) }{ }^{c}(B 1) \\
\text { - Sofosbuvir/daclatasvir (A1) }{ }^{d}(B 1)\end{array}$ & $\begin{array}{l}\text { Sofosbuvir/ } \\
\text { daclatasvir } \\
\text { - Sofosbuvir/RBV }\end{array}$ & $\begin{array}{l}\text { - Sofosbuvir/RBV }{ }^{c}(A 1) \\
\text { - Sofosbuvir/daclatasvir (A2) }{ }^{b} \text { (B2) }\end{array}$ \\
\hline
\end{tabular}

\footnotetext{
* Option for IFN ineligible patients;

\# All regimens: strong recommendation, low quality of evidence.

a With PegIFN- $\alpha$ in patients with cirrhosis;

${ }^{b}$ With RBV for 24 weeks in patients with cirrhosis;

C 24 weeks treatment;

d 24 weeks in patients with cirrhosis;

e With RBV in patients with cirrhosis.

Abbreviations: PegIFN, Pegylated interferon; RBV, Ribavirin.

All treatment courses are 12 weeks unless indicated otherwise.
} 
Lynch S.M. et al: Hepatitis C treatment, cost and barriers

Table 4a. Comparison of treatment guidelines for treatment-naïve patients infected with HCV genotype 4

\begin{tabular}{|c|c|c|c|}
\hline AASLD/IDSA & EASL & $\mathrm{WHO}^{*}$ & APASL \\
\hline $\begin{array}{l}\text { - Paritaprevir/ritonavir/ } \\
\text { ombitasvir/RBV (I-A) } \\
\text { - Sofosbuvir/velpatasvir (I-A) } \\
\text { Elbasvir/grazoprevir (IIa-B) } \\
\text { - Sofosbuvir/ledipasvir (IIa-B) }\end{array}$ & $\begin{array}{l}\text { PegIFN- } \alpha / \text { RBV/sofosbuvir (B1) } \\
\text { - PegIFN- } \alpha / \text { RBV/simeprevir, then } \\
\text { PegIFN- } \alpha / \text { RBV (24 weeks total) } \\
\text { (B1) } \\
\text { - Sofosbuvir/ledipasvir }{ }^{\text {ab }} \text { (B1) } \\
\text { - Paritaprevir/ritonavir/ombitasvir/ } \\
\text { RBV (A1) } \\
\text { - Sofosbuvir/simepravir }{ }^{\text {ab }} \text { (B2) } \\
\text { - Sofosbuvir/daciatasvir }{ }^{\text {ab }} \text { (B2) }\end{array}$ & $\begin{array}{l}\text { Sofosbuvir/daclatasvir }{ }^{\text {abc }} \\
\text { - Sofosbuvir/ledipasvir }{ }^{\text {b* }} \\
\text { Alternatives } \\
\text { Sofosbuvir/simepravir } \\
\text { - Ombitasvir/paritaprevir/ } \\
\text { ritonavir/RBV }\end{array}$ & $\begin{array}{l}\text { - Sofosbuvir/ledispavir }{ }^{a} \text { (A1) } \\
\text { - Sofosbuvir/velpatasvir } \\
(A 1)^{a}(B 1) \\
\text { - PrOD }{ }^{a} \text { (B1) } \\
\text { - Sofosbuvir/daclatasvir }{ }^{\text {ab }} \text { (B2) }\end{array}$ \\
\hline
\end{tabular}

\footnotetext{
* If the platelet count is $<75 \times 10^{3} / \mu \mathrm{L}$, then 24 weeks of treatment with RBV should be given;

\# All regimens: strong recommendation, moderate quality of evidence.

a 24 weeks in patients with cirrhosis;

b 12 weeks with RBV in patients with cirrhosis;

${ }^{\mathrm{C}}$ Can be used in patients with decompensated cirrhosis.

Abbreviations: PegIFN, Pegylated interferon; RBV, Ribavirin.

All treatment courses are 12 weeks unless indicated otherwise.
}

Table 4b. Comparison of treatment guidelines for treatment-experienced patients infected with HCV genotype 4

\begin{tabular}{|c|c|c|c|}
\hline AASLD/IDSA & EASL & $\mathrm{WHO}^{*}$ & APASL \\
\hline $\begin{array}{l}\text { - Paritaprevir/ritonavir/ } \\
\text { ombitasvir/RBV (I-A) } \\
\text { - Sofosbuvir/velapatasvir (I-A) } \\
\text { - Elbasvir/grazoprevir }{ }^{\mathrm{d}} \text { (IIa-B) } \\
\text { - Sofosbuvir/ledipasvir }{ }^{\mathrm{ab}} \text { (IIa-B) }\end{array}$ & $\begin{array}{l}\text { - PegIFN- } \alpha / \text { RBV/sofosbuvir (B1) } \\
\text { - PegIFN- } \alpha / \text { RBV/simeprevir, then } \\
\text { PegIFN- } \alpha / \text { RBV for } 36 \text { weeks } \\
\text { (48 weeks total) (B1) } \\
\text {. Sofosbuvir/ledipasvir }{ }^{\text {ab }} \text { (B1) } \\
\text { - Paritaprevir/ritonavir/ } \\
\text { ombitasvir/RBV (A1) }{ }^{\mathrm{a}} \\
\text { - Sofosbuvir/simepravir }{ }^{\text {ab }} \text { (B2) } \\
\text { - Sofosbuvir/daclatasvir }{ }^{\text {ab }} \text { (B2) }\end{array}$ & $\begin{array}{l}\text { - Sofosbuvir/daclatasvir }{ }^{\text {abc }} \\
\text { - Sofosbuvir/ledipasvir } \\
\text { Alternatives } \\
\text { - Sofosbuvir/simpepravir } \\
\text { - Paritaprevir/ritonavir/ } \\
\text { ombitasvir/RBV }\end{array}$ & $\begin{array}{l}\text { Sofosbuvir/ledispavir }{ }^{\mathrm{a}} \text { (A1) } \\
\text { Sofosbuvir/velpatasvir } \\
(\mathrm{A} 1)^{\mathrm{a}}(\mathrm{B} 1) \\
\text { - Paritaprevir/ritonavir/ } \\
\text { ombitasvir/dasabuvir }^{\mathrm{a}} \text { (B1) } \\
\text { - Sofosbuvir/daclatasvir }{ }^{\mathrm{ab}} \text { (B2) }\end{array}$ \\
\hline
\end{tabular}

\footnotetext{
* If the platelet count is $<75 \times 10^{3} / \mu \mathrm{L}$, then 24 weeks of treatment with RBV should be given;

\# All regimens: strong recommendation, moderate quality of evidence.

a 24 weeks in patients with cirrhosis;

b 12 weeks with RBV in patients with cirrhosis;

c Can be used in patients with decompensated cirrhosis;

d 16 weeks with RBV if prior PegIFN- $\alpha /$ RBV treatment failed.

Abbreviations: PegIFN, Pegylated interferon; RBV, Ribavirin.

All treatment courses are 12 weeks unless indicated otherwise.
}

RBV, sofosbuvir/velpatasvir, and elbasvir/grazoprevir. ${ }^{13}$ Sofosbuvir/daclatasvir with or without RBV is another option recommended by the EASL, WHO and APASL guidelines. ${ }^{9,10,12}$ Additional treatment options given by the WHO and EASL guidelines include simeprevir/sofosbuvir with or without RBV and ombitasvir/paritaprevir/ritonavir/RBV. ${ }^{9,12}$ The EASL guidelines recommend the combinations of PegIFN- $\alpha$ /simeprevir/RBV and PegIFN- $\alpha$ /sofosbuvir/RBV in addition to the IFN-free regimens ${ }^{9}$ (Table $4 a, 4 b$ ).

\section{Genotypes 5 and 6}

The treatment guidelines for HCV genotypes 5 and 6 are mostly adapted from studies on other genotypes, since specific data is lacking. The combination of sofosbuvir/ledispavir for 12 weeks is recommended by all four organizations. ${ }^{6,9,10,12}$ The treatment regimen of PegIFN- $\alpha$ /sofosbuvir/RBV is an additional treatment regimen recommended by the EASL guidelines and given as an alternative treatment option by the WHO guidelines. ${ }^{6,9,12}$ Sofosbuvir/daclatasvir with or without RBV is recommended by the EASL and APASL guidelines, based on data that daclatasvir acts against genotypes 5 and 6 in vitro. The APASL and AASLD/IDSA guidelines also recommend the newly-approved regimen of sofosbuvir/velpatasvir for treatment of HCV genotypes 5 and $6^{9,10}$ (Table 5a, 5b).

\section{Special populations}

\section{Cirrhotic patients}

Treatment regimens for HCV in patients with decompensated cirrhosis vary among the different societies' guidelines. The AASLD/IDSA guidelines recommend a 12-week course of RBV combined with ledipasvir/sofosbuvir, sofosbuvir/velpatasvir, or daclastavir/sofosbuvir for genotypes 1 and 4. This recommendation is for patients with moderate to severe hepatic impairment, who may or may not be transplant candidates or those with hepatocellular carcinoma. ${ }^{6}$ In patients who are RBV ineligible, treatment is extended to 24 weeks. In addition, the AASLD/IDSA guidelines recommend ledipasvir/sofosbuvir and sofosbuvir/velpatasvir for patients who failed a sofosbuvirbased regiment with a prolonged 24-week course of treatment. The AASLD/IDSA guidelines also strongly recommend that these patients be referred to a specialist for treatment. ${ }^{13}$ 
Lynch S.M. et al: Hepatitis C treatment, cost and barriers

Table 5a. Comparison of treatment guidelines for treatment naïve patients infected with HCV genotypes 5 and 6

\begin{tabular}{|c|c|c|c|}
\hline AASLD/IDSA & EASL & $\mathrm{WHO}^{\#}$ & APASL \\
\hline $\begin{array}{l}\text { - Sofosbuvir/velpatasvir (I-A) } \\
\text { - Sofosbuvir/ledipasvir(IIa-B) }\end{array}$ & $\begin{array}{l}\text { - PegIFN- } \alpha / \text { RBV/sofosbuvir (B1) } \\
\text { - Sofosbuvir/ledipasvir }{ }^{\text {abc }} \text { (B1) } \\
\text { - Sofosbuvir/daclatasvir }{ }^{\text {ab }} \text { (B1) }\end{array}$ & 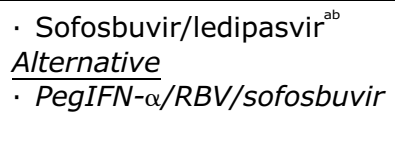 & $\begin{array}{l}\text { - Sofosbuvir/velatasvir (A1) } \\
\text { in cirrhosis (B1) } \\
\text { - Sofosbuvir/ledipasvir }{ }^{\mathrm{a}} \text { (B1) } \\
\text { - Sofosbuvir/daclatasvir }\end{array}$ \\
\hline
\end{tabular}

* If the platelet count is $<75 \times 10^{3} / \mu \mathrm{L}$, then 24 weeks of treatment with RBV should be given;

\# All regimens: conditional recommendation, very low quality of evidence.

a 24 weeks in patients with cirrhosis;

b 12 weeks with RBV in patients with cirrhosis;

C 24 weeks with RBV if negative predictors of response.

Abbreviations: PegIFN, Pegylated interferon; RBV, Ribavirin.

All treatment courses are 12 weeks unless indicated otherwise.

Table 5b. Comparison of treatment guidelines for treatment-experienced patients infected with genotype 5 and 6

\begin{tabular}{|c|c|c|c|}
\hline AASLD/IDSA & EASL & WHO & APASL \\
\hline $\begin{array}{l}\text { Sofosbuvir/velpatasvir (IIa-B) } \\
\text { Sofosbuvir/ledipasvir(IIa-C) }\end{array}$ & $\begin{array}{l}\text { - PegIFN- } \alpha / \text { RBV/sofosbuvir (B1) } \\
\text { - Sofosbuvir/ledipasvir }{ }^{\text {abc }} \text { (B1) } \\
\text { - Sofosbuvir/daclatasvir }{ }^{\text {ab }} \text { (B1) }\end{array}$ & $\begin{array}{l}\text { Sofosbuvir/ledipasvir }{ }^{\text {ab }} \\
\frac{\text { Alternative }}{\text { PegIFN- } \alpha / R B V /} \\
\text { sofosbuvir }\end{array}$ & $\begin{array}{l}\text { - Sofosbuvir/velatasvir (A1) } \\
\text { in cirrhosis (B1) } \\
\text { - Sofosbuvir/ledipasvir }{ }^{\mathrm{a}} \text { (B1) } \\
\text { - Sofosbuvir/daclatasvir }{ }^{\mathrm{ab}} \text { (B1) }\end{array}$ \\
\hline
\end{tabular}

\footnotetext{
* If the platelet count is $<75 \times 10^{3} / \mu \mathrm{L}$, then 24 weeks of treatment with RBV should be given;

\# All regimens: conditional recommendation, very low quality of evidence.

a 24 weeks in patients with cirrhosis;

b 12 weeks with RBV in patients with cirrhosis;

c 24 weeks with RBV if negative predictors of response.

Abbreviations: PegIFN, Pegylated interferon; RBV, Ribavirin.

All treatment courses are 12 weeks unless indicated otherwise.
}

The EASL guidelines recommend ledipasvir/sofosbuvir for genotypes 1, 4, 5 and 6, along with sofosbuvir and RBV for 16-20 weeks for genotype 2, and sofosbuvir/daclatasvir with RBV for 12 weeks for all genotypes. ${ }^{9}$ The APASL guidelines are similar, recommending sofosbuvir-based treatment, with or without ledipasvir (genotype 1) or daclatasvir (genotype 3 ) for $12-24$ weeks. ${ }^{16}$ According to the WHO guidelines, simeprevir and the combination of ombitasvir/paritaprevir/ ritonavir/dasabuvir are not approved for patients with decompensated cirrhosis. While the WHO guidelines recognize daclatasvir, ledipasvir and sofosbuvir as feasible and effective in patients with decompensated liver disease, they recommend that treatment be restricted to specialized centers in order to manage complications, and preferably those centers where liver transplantation is available. ${ }^{12}$

\section{HIV co-infection}

HCV-infected patients that are co-infected with human immunodeficiency virus (HIV) are generally treated the same as HIV-negative individuals, but there are certain precautions that need to be considered. The APSAL guidelines suggest deferring treatment for $\mathrm{HCV}$ infection until the CD4 count is $>200$ cells $/ \mathrm{mm}^{3}$. Across all the guidelines, the main area of concern in HCV/HIV co-infected patients is medication interactions, and treatment should be coordinated with an expert. ${ }^{1,9,10,13}$ Avoidance of tenofovir is recommended while using ledipasvir/sofosbuvir, as the latter potentiates the nephrotoxic effect of tenofovir disoproxil fumarate (TDF), especially in combination with other antivirals. A possible alternative for TDF is tenofovir alafenamide (TAF). ${ }^{13}$ In addition, when using PrOD, rilpivirine and efavirenz should not be used, as the ritonavir potentiates HIV protease inhibitors, leading to an increase in gastrointestinal side effects, neurologic events and aminotransferase elevations. ${ }^{6,10}$

\section{Renal impairment}

The AASLD/IDSA guidelines state that DAA's can be safely dosed in patients with mild to moderate renal impairment (creatinine clearance $(\mathrm{CrCl})$ rate of $30-80 \mathrm{~mL} / \mathrm{min})$. For patients with severe renal impairment/end-stage renal disease $(\mathrm{CrCl}$ rate of $<30 \mathrm{~mL} / \mathrm{min})$ in whom treatment has been elected before renal transplant, the AASLD/IDSA guidelines recommend the following regimens: PrOD for genotype $1 \mathrm{~b}$ and elbasvir/grazoprevir for genotypes 1 and 4. For genotypes $2,3,5$ or 6 , PegINF- $\alpha$ with RBV can be used. RBV may be added to the regimen if the hemoglobin is $>10 \mathrm{~g} / \mathrm{dL}$, but caution should be used because of the risk of hemolytic anemia. ${ }^{6,13}$ For patients with an estimated glomerular filtration rate (eGFR) of $30-50 \mathrm{~mL} / \mathrm{min}$, RBV can be given at doses of $200 \mathrm{mg}$ and $400 \mathrm{mg}$ on alternating days. ${ }^{6}$

The EASL guidelines recommend that hemodialysis (HD) patients who are suitable for transplant be treated with antivirals. Although they do not state a specific agent, they recommend IFN-free regimens and, if possible, RBV-free. The EASL guidelines also recommend PrOD for patients with severe renal impairment and specifically state that sofosbuvir should 
Lynch S.M. et al: Hepatitis C treatment, cost and barriers

not be administered to patients with eGFR of $<30 \mathrm{~mL} / \mathrm{min}^{9}$ The APASL guidelines are comparable to the AASLD/IDSA guidelines with regards to patients with mild to moderate renal impairment $(\mathrm{CrCl}$ rate of $30-80 \mathrm{~mL} / \mathrm{min}){ }^{6,10}$ In addition, the APASL guidelines recommend that simeprevir be given at its standard dose for patients with severe renal impairment ( $\mathrm{CrCl}$ rate of $<30 \mathrm{~mL} / \mathrm{min}$ ).

The APSAL guidelines pay special attention to the lack of access to DAAs in many Asian countries. Given the variability in access to DAAs, they suggest referring to the 2012 guidelines for IFN-based treatment regimens for patients with renal impairment. ${ }^{10}$ In accordance with the EASL guidelines, the WHO guidelines report that sofosbuvir lacks safety data in patients with renal impairment. ${ }^{9,12}$ They also compare PegINF- $\alpha 2 a$ and PegINF- $\alpha 2 b$, the latter being excreted via the kidneys, and state that although there is a theoretical accumulation of PegINF- $\alpha 2 b$ in patients with $H D$, there was no difference clinically. In patients with $\mathrm{CrCl}$ of $20-40 \mathrm{~mL} /$ min, PegINF $\alpha-2 a$ should be dosed at $135 \mu \mathrm{g} /$ week, with a reduced RBV dose. In patients with HD, the RBV may be administered at $200 \mathrm{mg} /$ day or every other day. ${ }^{12}$

\section{Barriers to treatment}

Although DAA agent-only regimens are recommended as first-line therapy for the treatment of HCV infection, access to these medications has proven to be limited by multiple factors. Even in the era of DAAs, HCV-infected individuals may not clear the virus. The reasons for this include host and viral factors, as well as compliance and accessibility. The latter are usually due to the healthcare system itself. ${ }^{17}$ Common issues leading to limited access to treatment include insurance concerns, low health literacy, and lack of consistent medical care. In addition, patients may have competing health concerns, such as mental illness, comorbidities, substance abuse, lack of social support and homelessness. Patients may be unemployed or under-employed, and prior to the advent of DAAs, many patients feared the side effects of IFN-based therapy. ${ }^{17}$

In a study by Stepanova et al., ${ }^{18}$ the rate of insurance coverage for HCV patients ranged from $60 \%-65 \%$, and many of the individuals were also found to be underinsured. DAAs have proven to be highly effective but at an extremely high cost, which serves as a major barrier to more widespread treatment access. ${ }^{19}$ Although cost is a common barrier to treatment access worldwide, additional barriers can be identified, which vary based on a country's economic status.

\section{Low- and middle-income countries (LMIC)}

LMIC have a high rate of endemicity of chronic HCV infection. Based on the World Bank classification, LMIC are countries with a gross national income (GNI) per capita of less than $\$ 1,045$ for low-income countries and less the $\$ 12,735$ for middle-income countries ${ }^{20}$ (Table 6). For LMIC, in addition to access to medications, testing required for appropriate selection of agents may not be readily available. ${ }^{21}$ Unlike HIV infection, for which most of the affected people live on the African continent, most of the 185 million people with chronic HCV infection live in Asia. ${ }^{21,22}$ Specifically, the majority of HCV-infected individuals live in middle-income countries such as China, Pakistan and Nigeria. ${ }^{21}$ This is an important
Table 6. AASLD-IDSA recommendations for patients who would receive the most immediate benefits from treatment

Highest-priority for treatment High-priority for owing to highest risk for treatment owing to high severe complications risk for complications

\begin{tabular}{ll}
\hline $\begin{array}{l}\text { Advanced fibrosis (METAVIR } \\
\text { F4) or compensated (METAVIR }\end{array}$ & Fibrosis (METAVIR F2) \\
Organ transplant recipients & HIV-1 coinfection \\
$\begin{array}{l}\text { Type } 2 \text { or } 3 \text { cryoglobulinemia } \\
\text { with end-organ manifestations } \\
\text { (e.g., vasculitis) }\end{array}$ & $\begin{array}{l}\text { Hepatitis B virus } \\
\text { coinfection }\end{array}$ \\
$\begin{array}{l}\text { Proteinuria, nephrotic } \\
\text { syndrome or }\end{array}$ & $\begin{array}{l}\text { Other coexistent liver } \\
\text { membranoproliferative } \\
\text { glomerulonephritis }\end{array}$ \\
& $\begin{array}{l}\text { nonalcoholic } \\
\text { steatohepatitis) }\end{array}$ \\
& Debilitating fatigue \\
& $\begin{array}{l}\text { Type 2 Diabetes mellitus } \\
\text { (insulin-resistant) }\end{array}$ \\
& Porphyria cutanea tarda \\
\hline
\end{tabular}

Abbreviation: HIV, Human immunodeficiency virus.

distinction because these Asian countries do not attract traditional financial aid when compared to African countries. ${ }^{23}$

Drug pricing remains the major barrier to treatment with DAAs, and some progress has been made in this area. For example, in Egypt, where the government has worked with pharmaceutical companies to reduce prices, the list price for a 12 -week treatment with sofosbuvir has dropped to $\$ 900 .^{21,22}$ Attempts to make recommended HCV treatment available has also been seen in India. A voluntary licensing agreement was announced by Gilead Sciences, Inc, enabling 11 Indian manufacturers to make their generics available to 103 LMICs, excluding China. ${ }^{21,22}$ This allows countries to obtain low-cost generics which retail at about $1 \%-2 \%$ of the United States'

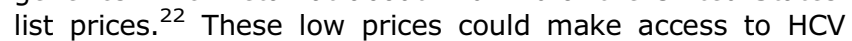
treatment in LMIC a realistic goal. ${ }^{21}$ Furthermore, the success of global HIV treatment initiatives provides the precedent for successful therapeutic intervention for the management of a chronic viral infection. ${ }^{22}$

\section{High-income countries}

Barriers to accessing DAAs are not limited to LMIC, as DAAs are expensive and resources are limited even in high-income countries. High-income countries are defined as countries with a GNI per capita greater then $\$ 12,736 .{ }^{20}$ Although DAAs have been shown to be, for the most part, cost-effective, they have not proven to be affordable. ${ }^{6}$ Data from the IFN era reveals that $\sim 16 \%$ of $\mathrm{HCV}$-infected individuals were prescribed antiviral treatment, with only $9 \%$ achieving SVR. ${ }^{24}$ Given the significant number of undiagnosed patients with chronic HCV infection, this number is sobering and illustrates that cost is not the only barrier to DAAs. Certain barriers can be seen worldwide and regardless of income, which include diagnosis, lack of knowledge of treatment options, medical eligibility, infrastructure for vulnerable populations and high cost. ${ }^{24,25}$

Despite limitations in the diagnosis and treatment of chronic HCV, the single most important determinant of 
Table 7. Common prior authorization criteria for sofosbuvir prescription under state Medicare fee-for-service programs

Common prior authorization requirements for sofosbuvir

- Abstain from alcohol use before treatment

- Abstain from alcohol abuse before treatment

- Abstain from drug use before treatment

- Abstain from injection drug use before treatment

- Minimum METAVIR fibrosis score

- Specialist provider

accessibility to DAAs in the United States' is cost. Many insurance companies and most Medicaid programs in the United States currently only approve payment for patients with advanced liver fibrosis or other high-priority patients as described by the AASLD/IDSA HCV guidance sections ${ }^{19,26,27}$ (Table 7). Liver fibrosis is measured by the METAVIR fibrosis score, with scores of F3 and F4 designating a patient as "highest-priority" and a score of F2 designating a patient as "high-priority". 6,28 High-priority patients include those who are recipients of organ transplant, or have type 2 or 3 cryoglobulinemia with end organ manifestation, renal involvement (nephrotic syndrome, membranoproliferative glomerulonephritis), HIV-1 or hepatitis B co-infection, other liver disease, debilitating fatigue, diabetes mellitus type 2 or porphyria cutanea tarda. ${ }^{6}$ Providers face significant delays, which could lead to lack of treatment and loss to follow-up. ${ }^{19}$ In addition, to date, insurance carriers do not have a uniform policy as to who qualifies for treatment using DAAs, and each state in the United States has its own Medicaid program regarding HCV treatment. ${ }^{19}$

In a study conducted by Saab et al., ${ }^{26}$ among the 410 patients prescribed DAAs between October 2014 and July 2015, 81\% were insurance-approved for therapy. Various factors were found to be associated with approval, including older age, employment, lack of comorbidities, liver transplantation and advanced liver disease. Furthermore, Medicare insurance, lack of non-liver comorbidities and presence of advanced liver disease were found to be independent predictors of drug approval. Medicaid insurance was also found to be associated with a high insurance denial rate for treatment with DAAs. $^{26}$

These results echo some of the results from a study by Do et al., ${ }^{24}$ which found that one in four patients were initially denied access to sofosbuvir and ledipasvir, although most were eventually approved. The initial denial led to delays in the initiation of treatment, however. Interestingly, this study also found that having Medicare/Medicaid coverage resulted in a higher likelihood of approval than private insurance for the same stages of advanced liver disease. Unfortunately, this study was limited in that it did not distinguish between Medicare and Medicaid, and was carried out at a date that preceded prior authorization guidelines. ${ }^{24}$

The denial rate for Medicaid is concerning because as many as $25 \%$ of patients in the United States with chronic HCV who are hospitalized are covered by Medicaid. There are many state requirements set forth by Medicaid that further restrict approval of DAAs for treatment of HCV infection. In a study conducted by Barua et al., ${ }^{27}$ Medicaid programs in 31 states were found to designate sofosbuvir as "not preferred", with four states being found to require liver biopsy to prove the level of fibrosis, rather than allowing less invasive testing.
Seventeen states were found to apply a "preferred" designation to sofosbuvir, and although proving medical necessity was not required, 15 of these 17 states required "prior authorization". There were also 30 states that were found to require sofosbuvir be prescribed in consultation with a specialist. ${ }^{27,28}$ It was also reported that many states also require drug screening, which further delays treatment to patients with chronic HCV and adds to the expense of their management, even though these patients reportedly showed similar rates of adherence to treatment as the general population. Additional hurdles include limiting service based on CD4 count. ${ }^{27,28}$

These restrictions are clearly contrary to Medicaid guidelines. Effective November 2015, the Centers for Medicare and Medicaid Services (CMS) released guidance in which they addressed restrictions on DAA treatments for HCV. It was noted that although states have the discretion to establish limitations on coverage, they must ensure access to clinically appropriate treatment. ${ }^{19}$ Furthermore, limiting treatment based on fibrosis, requiring abstinence and limiting the type of providers able to prescribe HCV treatment were cited as examples of unreasonable restrictions. ${ }^{19}$ As noted by Edlin, ${ }^{29}$ selective denial of medically necessary care for high-cost conditions is a discriminator, and illegal under the Affordable Care Act (Table 7).

Finally, another major hurdle to the treatment of chronic $\mathrm{HCV}$ infection is the pharmacy benefit manager (PBM). These are generally for-profit intermediaries in the pharmacy supply chain, who greatly influence the actual drug cost. ${ }^{6,19}$ As noted in a review by Rosenthal et al., ${ }^{30}$ the pricing between pharmaceutical companies and PBMs are confidential business dealings that prevent transparency. These transactions can potentially have negative impacts on drug pricing and free market competition. In addition, PBMs often negotiate contracts with pharmaceutical companies with exclusivity, creating restrictions on prescription medications. ${ }^{6}$

\section{Cost-effectiveness of DAAs}

Cost-effectiveness analysis (CEA) is a means of evaluating budget limitations for healthcare spending and seeks to balance public health needs with budget constraints. ${ }^{6}$ When discussing the cost-effectiveness of DAAs, it is important to note that the "cost" of a publically available drug is the wholesale acquisition cost. The actual price paid for the medication by health insurers varies. ${ }^{6,19}$ CEA is a formal method to compare the cost and outcomes between two interventions, one being the standard of care. This is measured using the incremental cost-effectiveness ratio (ICER). ${ }^{19,31-33}$ The ICER in HCV infection treatment is usually measured as a cost per quality-adjusted life years (QALY) gained between two treatment strategies. In the United States, the willingness to pay threshold is $\$ 50,000-\$ 100,000$ per QALY gained. $6,19,33$ DAAs for HCV infection appear to be cost effective when compared to prior therapies. However, the benefit to society and the payer would not be seen until at least a decade later (Table 8). The projected cost of widespread use of DAAs for treatment of HCV infection in the United States would exceed $\$ 300$ billion, which is not feasible. $6,19,34$ The cost-effectiveness of DAAs is currently affected by the drug prices and the patient populations selected as noted by Chhatwal et al. ${ }^{33}$

Many cost-effectiveness studies have examined sofosbuvir and ledipasvir for treatment of genotype 1 infections. From these studies, it was determined that, in certain patients, HCV treatment with DAAs was cost-effective, with most ICERs 
Table 8. Incremental cost-effectiveness ratio (ICER) per qualityadjusted life year (QALY) based on HCV genotype

\begin{tabular}{ll}
\hline $\begin{array}{l}\text { Hepatitis C virus } \\
(\mathrm{HCV}) \text { genotype }\end{array}$ & ICERs per QALY \\
\hline 1 & $\begin{array}{l}\text { Treatment-naïve: less than } \$ 0 \text { to } \\
\$ 31,452^{2}\end{array}$ \\
& $\begin{array}{l}\text { Interferon-experienced patients: } \\
\$ 84,744 \text { to } \$ 178,295\end{array}$ \\
& US\$ 35,500 to US $\$ 238,000^{2,3}$ \\
3 & US $\$ 410,518^{2}$ \\
4 & US $\$ 34,349$ to US $\$ 80,793^{2}$ \\
\hline
\end{tabular}

${ }^{1}$ When the ICER is determined, it is compared to the willingness to pay threshold, which is typically considered $\$ 50,000$ to $\$ 100,000 / Q A L Y ;$

2 Depending on presence or absence of cirrhosis;

${ }^{3}$ In treatment-naïve patients without cirrhosis, the manufactures price for sofosbuvir led to ICERs above the willingness to pay threshold. Negotiating lower cost can lead to ICERs dropping to acceptable levels.

being less than $\$ 100,000$. $^{6,19}$ In addition to the cost of the drug, age and severity of fibrosis were significant influencers of the ICERs. The greatest cost savings were seen in younger patients and in patients with advanced fibrosis. Certain exceptions to this were seen, however, including patients who required 24 weeks of treatment and patients with cirrhosis. $6,19,33,35,36$ Treatment of genotype 2 or 3 with DAA agent-only regimens is reportedly less cost-effective when compared to genotype 1 , likely due to the fact that most patients achieve cure with PegIFN- $\alpha$ based therapy. $6,19,32,35$

There are limitations encountered when interpreting costeffectiveness data for the treatment of HCV with DAAs. One of the limitations is that the price of the DAAs used is the wholesale acquisition cost, which is generally not the price paid by insurers. The actual acquisition cost negotiated by PBMs is not publicly available, however. ${ }^{35}$ In addition, many studies have not taken into account indirect costs, nonmedical costs, comorbid conditions and other political, societal or ethical priorities. ${ }^{6,19,31,32,35}$ In a recent systemic review of analytic models for determining the cost-effectiveness of DAAs, it was shown that most modeling studies have used similar structures and have underestimated the value of $\mathrm{HCV}$ treatment. ${ }^{37}$

\section{Future directions}

As we move into the era of pangenotypic, RBV-free DAA regimens, there remain obstacles to broad implementation of these therapies, including screening and disease assessment, public health prioritization and drug pricing. ${ }^{22}$ DAAs are a powerful tool in the fight against chronic HCV. However, an effective treatment is not enough. The eradication of $\mathrm{HCV}$ will require a significant amount of financial investment for screening, prevention and treatment. As noted by Hesamizadeh et al., ${ }^{38}$ the next steps in the eradication of chronic HCV involves finding and treating patients with chronic HCV in the general population, improving the availability and affordability of treatment (particularly in LMIC), and focusing on certain special populations, such as patients with HIV co-infection, kidney disease, thalassemia and liver transplant recipients. All of these goals need to be accomplished while concentrating on education and prevention simultaneously. ${ }^{38}$
Globally, pharmaceutical companies will need to continue to work directly with governments to negotiate cheaper generic versions of the medications, while also weighing their need for profit. ${ }^{21,38}$ LMIC will need to address issues related to access to healthcare and health literacy, a potential model for this being the one used to implement HIV treatments. ${ }^{39}$ In the United States, the process will need to become more transparent, as cost-effectiveness is determined by the cost of the treatment. At the current time, it is unclear if the pharmaceutical industry operates by the same free market rules seen in other industries, as noted in the review by Rosenthal et al. ${ }^{30,40}$ In addition, it may be prudent to consider a uniform national policy to identify who qualifies for treatment with DAAs. Taking some of these steps will, hopefully, align with the WHO's goal of eradication of HCV by 2030. As noted by Afdhal et al., ${ }^{17}$ "in the US, HCV has all the attributes of an eradicable disease except sufficient public investment. Delivering care effectively, safely and broadly to all patient populations in an economically acceptable fashion must be our goal." In addition, future CEA needs to take into account the benefits of treating HCV, including preventing transmission, and performance in LMIC. ${ }^{37}$

The recent approval by the United States' FDA of sofosbuvir/velpatasvir, the first regimen able to treat all $6 \mathrm{HCV}$ genotypes, opens the door for the next stage in DAA agentonly treatment regimens. ${ }^{15}$ As reported in the ASTRAL 1-4 trials, this combination had excellent SVR in genotypes $1-6 .{ }^{41-43}$ In the study by Hill et al. ${ }^{44}$ the cost of large-scale treatment access programs was analyzed in developing countries, and further research needs to be conducted to ensure pan-genotypic coverage of HCV.

\section{Conclusions}

Guidelines around the world have been updated to reflect the efficacy and tolerability of DAAs, while also considering regional economic differences. The excitement of the IFNfree DAA era, however, has been dampened by the extremely high cost of these medications. Although there are many barriers to access to these medications, cost remains the single biggest barrier to the widespread use of DAAs. Most of the new treatment regimens have been shown to be costeffective. However, given the disease burden, the widespread implementation of treatment is not feasible or affordable at the current time in most of the world. ${ }^{31-35,40}$ Much work still needs to be done in order to make guideline-driven DAAbased treatment universally affordable and accessible, to achieve the ultimate goal of eradication of chronic HCV infection.

\section{Conflict of interest}

None

\section{Author contributions}

Drafted the manuscript (SML), critically revised the manuscript (GYW).

\section{Acknowledgments}

Support from the Herman Lopata Chair in Hepatitis Research and a research grant from Alexion Corp. is gratefully acknowledged. 


\section{References}

[1] World Health Organization. Guidelines for the screening, care, and treatment of persons with hepatitis C infection. Available from: http://apps.who.int/iris/ bitstream/10665/111747/1/9789241548755_eng.pdf?ua, accessed April 2014.

[2] Lavanchy D. Evolving epidemiology of hepatitis C virus. Clin Microbiol Infect 2011;17:107-115. doi: 10.1111/j.1469-0691.2010.03432.x.

[3] Denniston MM, Jiles RB, Drobeniuc J, Klevens RM, Ward JW, McQuillan GM, et al. Chronic hepatitis $C$ virus infection in the United States, National Health and Nutrition Examination Survey 2003 to 2010. Ann Intern Med 2014;160: 293-300. doi: 10.7326/M13-1133.

[4] Lo Re V 3rd, Gowda C, Urick PN, Halladay JT, Binkley A, Carbonari DM, et al. Disparities in absolute denial of modern hepatitis $C$ therapy by type of insurance. Clin Gastroenterol Hepatol 2016;14:1035-1043. doi: 10.1016/j. cgh.2016.03.040.

[5] Mohd Hanafiah K, Groeger J, Flaxman AD, Wiersma ST. Global epidemiology of hepatitis $C$ virus infection: new estimates of age-specific antibody to HCV seroprevalence. Hepatology 2013;57:1333-1342. doi: 10.1002/hep.26141.

[6] AASLD/IDSA HCV Guidance Panel. Hepatitis C guidance: AASLD-IDSA recommendations for testing, managing, and treating adults infected with hepatitis C virus. Hepatology 2015;62:932-954. doi: 10.1002/hep.27950.

[7] Mahajan R, Liu SJ, Klevens RM, Holmberg SD. Indications for testing among reported cases of $\mathrm{HCV}$ infection from enhanced hepatitis surveillance sites in the United States, 2004-2010. Am J Public Health 2013;103:1445-1449. doi: 10.2105/AJPH.2013.301211.

[8] Denniston MM, Klevens RM, McQuillan GM, Jiles RB. Awareness of infection, knowledge of hepatitis $C$, and medical follow-up among individuals testing positive for hepatitis C: National Health and Nutrition Examination Survey 2001-2008. Hepatology 2012;55:1652-1661. doi: 10.1002/hep.25556.

[9] European Association for Study of Liver. EASL recommendations on treatment of hepatitis C 2015. J Hepatol 2015;63:199-236. doi: 10.1016/j. jhep.2015.03.025.

[10] Omata M, Kanda T, Wei L, Yu ML, Chuang WL, Ibrahim A, et al. APASL consensus statements and recommendations for hepatitis $C$ prevention, epidemiology, and laboratory testing. Hepatol Int 2016;10:681-701. doi: $10.1007 / \mathrm{s} 12072-016-9736-3$.

[11] Wedemeyer H, Dore GJ, Ward JW. Estimates on HCV disease burden worldwide - filling the gaps. J Viral Hepat 2015;22 Suppl 1:1-5. doi: 10.1111/ jvh.12371.

[12] World Health Organization. Guidelines for the screening, care and treatment of persons with chronic hepatitis C infection. Available from: http://www. who.int/hepatitis/publications/hepatitis-c-guidelines-2016/en/, accessed April 2016.

[13] AASLD-IDSA. Recommendations for testing, managing, and treating hepatitis C. Available from: http://hcvguidelines.org/sites/default/files/ HCV-Guidance_October_2016_a.pdf, accessed September 2016.

[14] Badri PS, King JR, Polepally AR, McGovern BH, Dutta S, Menon RM. Dosing recommendations for concomitant medications during 3D anti-HCV therapy. Clin Pharmacokinet 2016;55:275-295. doi: 10.1007/s40262-015-0317-8.

[15] U.S. Food and Drug Administration. FDA approves Epsclusa for treatment of chronic Hepatitis C virus infection. Available from: http://www.fda.gov/ NewsEvents/Newsroom/PressAnnouncements/ucm508915.htm, accessed June 2016.

[16] Omata M, Kanda T, Wei L, Yu ML, Chuang WL, Ibrahim A, et al. APASL consensus statements and recommendation on treatment of hepatitis $C$ Hepatol Int 2016;10:702-726. doi: 10.1007/s12072-016-9717-6.

[17] Afdhal NH, Zeuzem S, Schooley RT, Thomas DL, Ward JW, Litwin AH, et al. The new paradigm of hepatitis $C$ therapy: integration of oral therapies into best practices. J Viral Hepat 2013;20:745-760. doi: 10.1111/jvh.12173.

[18] Stepanova M, Younossi ZM. Interferon-free regimens for chronic hepatitis C: barriers due to treatment candidacy and insurance coverage. Dig Dis Sci 2015;60:3248-3251. doi: 10.1007/s10620-015-3709-6.

[19] Woolston SL, Kim HN. Cost and access to direct-acting antiviral agents. Available from: http://www.hepatitisc.uw.edu/go/evaluation-treatment/ cost-access-medications/core-concept/all\# cost-effectiveness-direct-actingantiviral-agents, accessed July 2016.

[20] World bank country and lending groups. Available from: https://datahelpdesk.worldbank.org/knowledgebase/articles/906519-world-bank-countryand-lending-groups.

[21] Zoulim F, Liang TJ, Gerbes AL, Aghemo A, Deuffic-Burban S, Dusheiko G, et al. Hepatitis $C$ virus treatment in the real world: optimising treatment and access to therapies. Gut 2015;64:1824-1833. doi: 10.1136/gutjnl2015-310421.
[22] Dore GJ, Feld J]. Hepatitis C virus therapeutic development: in pursuit of "perfectovir". Clin Infect Dis 2015;60:1829-1836. doi: 10.1093/cid/civ197.

[23] Sumner A. The new bottom billion: what if most of the world's poor live in middle income countries? CGD Brief. Available from: http://www.cgdev.org/ sites/default/files/1424922_file_Sumner_brief_MIC_poor_FINAL.pdf, accessed March 2011.

[24] Do A, Mittal Y, Liapakis A, Cohen E, Chau H, Bertuccio C, et al. Drug authorization for sofosbuvir/ledipasvir (harvoni) for chronic HCV infection in a realworld cohort: a new barrier in the HCV care cascade. PLoS One 2015;10: e0135645. doi: 10.1371/journal.pone.0135645.

[25] Chak EW, Sarkar S, Bowlus C. Improving healthcare systems to reduce healthcare disparities in viral hepatitis. Dig Dis Sci 2016;61:2776-2783. doi: 10.1007/s10620-016-4205-3.

[26] Saab S, Jimenez M, Fong T, Wu C, Bau S, Jamal Z, et al. Accessibility to oral antiviral therapy for patients with chronic hepatitis $C$ in the United States. J Clin Transl Hepatol 2016;4:76-82. doi: 10.14218/JCTH.2016.00011.

[27] Barua S, Greenwald R, Grebely J, Dore GJ, Swan T, Taylor LE. Restrictions for medicaid reimbursement of sofosbuvir for the treatment of hepatitis $C$ virus infection in the United States. Ann Intern Med 2015;163:215-223. doi: 10.7326/M15-0406.

[28] Canary LA, Klevens RM, Holmberg SD. Limited access to new hepatitis C virus treatment under state medicaid programs. Ann Intern Med 2015; 163:226-228. doi: 10.7326/M15-0320.

[29] Edlin BR. Access to treatment for hepatitis $C$ virus infection: time to put patients first. Lancet Infect Dis 2016;16:e196-e201. doi: 10.1016/S14733099(16)30005-6.

[30] Rosenthal ES, Graham CS. Price and affordability of direct-acting antiviral regimens for hepatitis $C$ virus in the United States. Infect Agent Cancer 2016;11:24. doi: 10.1186/s13027-016-0071-z.

[31] Leidner AJ, Chesson HW, Xu F, Ward JW, Spradling PR, Holmberg SD. Costeffectiveness of hepatitis $C$ treatment for patients in early stages of liver disease. Hepatology 2015;61:1860-1869. doi: 10.1002/hep.27736.

[32] Linas BP, Barter DM, Morgan JR, Pho MT, Leff JA, Schackman BR, et al. The cost-effectiveness of sofosbuvir-based regimens for treatment of hepatitis $C$ virus genotype 2 or 3 infection. Ann Intern Med 2015;162:619-629. doi: 10.7326/M14-1313.

[33] Chhatwal J, Kanwal F, Roberts MS, Dunn MA. Cost-effectiveness and budget impact of hepatitis $C$ virus treatment with sofosbuvir and ledipasvir in the United States. Ann Intern Med 2015;162:397-406. doi: 10.7326/M141336.

[34] Rein DB, Wittenborn JS, Smith BD, Liffmann DK, Ward JW. The costeffectiveness, health benefits, and financial costs of new antiviral treatments for hepatitis C virus. Clin Infect Dis 2015;61:157-168. doi: 10.1093/cid/ civ220.

[35] Najafzadeh M, Andersson K, Shrank WH, Krumme AA, Matlin OS, Brennan T, et al. Cost-effectiveness of novel regimens for the treatment of hepatitis $C$ virus. Ann Intern Med 2015;162:407-419. doi: 10.7326/M14-1152.

[36] Younossi ZM, Park H, Saab S, Ahmed A, Dieterich D, Gordon SC. Costeffectiveness of all-oral ledipasvir/sofosbuvir regimens in patients with chronic hepatitis $C$ virus genotype 1 infection. Aliment Pharmacol Ther 2015;41:544-563. doi: 10.1111/apt.13081.

[37] Chhatwal J, He T, Lopez-Olivo MA. Systematic review of modelling approaches for the cost effectiveness of hepatitis $C$ treatment with directacting antivirals. Pharmacoeconomics 2016;34:551-567. doi: 10.1007/ s40273-015-0373-9.

[38] Hesamizadeh K, Sharafi H, Rezaee-Zavareh MS, Behnava B, Alavian SM. Next steps toward eradication of hepatitis $C$ in the era of direct acting antivirals. Hepat Mon 2016;16:e37089. doi: 10.5812/hepatmon.37089.

[39] Graham CS, Swan T. A path to eradication of hepatitis C in low- and middleincome countries. Antiviral Res 2015;119:89-96. doi: 10.1016/j. antiviral.2015.01.004.

[40] Saag MS. Editorial commentary: getting smart in how we pay for HCV drugs: KAOS vs CONTROL. Clin Infect Dis 2015;61:169-170. doi: 10.1093/cid/ civ221.

[41] Feld J], Zeuzem S. Sofosbuvir and Velpatasvir for patients with HCV infection. N Engl J Med 2016;374:1688-1689.

[42] Curry MP, Charlton M. Sofosbuvir and velpatasvir for patients with HCV infection. N Engl J Med 2016;374:1688.

[43] Foster GR, Mangia A, Sulkowski M. Sofosbuvir and velpatasvir for patients with HCV infection. N Engl J Med 2016;374:1687-1688. doi: 10.1056/ NEJMc1601160.

[44] Hill A, Khoo S, Fortunak J, Simmons B, Ford N. Minimum costs for producing hepatitis $C$ direct-acting antivirals for use in large-scale treatment access programs in developing countries. Clin Infect Dis 2014;58:928-936. doi: $10.1093 /$ cid/ciu012. 